\title{
Radiological follow-up of twelve COVID-19 patients with initially normal chest CT
}

\author{
Chuanjun $\mathrm{Xu}^{1}$, Qiuzhen $\mathrm{Xu}^{2}$, Chao $\mathrm{Du}^{1}$, Jinlong $\mathrm{Li}^{3}$, Zhiliang $\mathrm{Hu}^{4,5}$, Yongxiang $\mathrm{Yi}^{4}$ \\ ${ }^{1}$ Department of Radiology, The Second Hospital of Nanjing, Nanjing University of Chinese Medicine, Nanjing 210003, China; ${ }^{2}$ Department of Radiology, \\ Zhongda Hospital Affiliated to Southeast University, Nanjing 210009, China; ${ }^{3}$ Department of Laboratory Medicine, The Second Hospital of Nanjing, \\ Nanjing University of Chinese Medicine, Nanjing 210003, China; ${ }^{4}$ Nanjing infectious Disease Center, The Second Hospital of Nanjing, Nanjing University \\ of Chinese Medicine, Nanjing 210003, China; ${ }^{5}$ Center for Global Health, School of Public Health, Nanjing Medical University, Nanjing 211166 , China
}

Correspondence to: Zhiliang Hu, MD; Yongxiang Yi, MD. Nanjing infectious Disease Center, The Second Hospital of Nanjing, Nanjing University of Chinese Medicine Nanjing, 1-1 Zhongfu Road, Nanjing 210003, China. Email: huzhiliangseu@163.com; ian0126@126.com.

Submitted Apr 06, 2020. Accepted for publication Apr 29, 2020.

doi: 10.21037/qims-20-539

View this article at: http://dx.doi.org/10.21037/qims-20-539

In December 2019, pneumonia related to coronavirus disease 2019 (COVID-19) was discovered in Wuhan, China. The causative pathogen of this novel disease was severe acute respiratory syndrome coronavirus 2 (SARS-CoV-2) (1). It is recognized that patients with COVID-19 may have variable degrees of disease severity, which may range from asymptomatic infection to life-threatening respiratory failure $(2,3)$. Because of its high capability of human-tohuman transmission, it spread rapidly in China (4). At present, COVID-19 has become a major public health issue of global concern. As of April 6, 2020, there were more than 1.2 million confirmed cases of COVID-19, leading to more than 67 thousand deaths (5).

To diagnose COVID-19 early and offer isolation is an important means to control the spread of the disease. At present, the diagnosis of COVID-19 is generally based on the positive nucleic acid test for SARS-CoV-2 using reverse transcription polymer chain reaction (RT-PCR) from the respiratory sample (6-8). It was reported that the sensitivity of chest CT in COVID-19 could be as high as $98 \%$ in selected samples (7). However, cautious should be taken when interpreting these results as there might be sampling bias, and it is possible that the sensitivity of chest CT may be lower in patients with milder disease (9). Some radiologists suggested that chest CT examination could be used as an important supplementary strategy in the epidemic area to screen suspected cases of COVID-19. If lung abnormalities are found on chest CT scans of patients with contact history, isolation measures could be taken immediately, and then followed by confirmation of the cases using nucleic acid test. In this regard, chest CT scan, when used as a screening strategy for COVID-19, may possibly help timely identification and isolation of the cases. Nevertheless, chest CT scan could be normal in patients with COVID-19, especially in those with asymptomatic infection $(2,10,11)$. However, it is less clear whether COVID-19 patients with baseline normal chest CT scans could develop pulmonary lesions during the full course of COVID-19 (12).

In the present study, we did radiological follow-up of 12 patients with COVID-19 who had normal chest CT when they presented to The Second Hospital of Nanjing, Nanjing, China. This study was approved by the ethics committee of the second hospital of Nanjing (reference number: 2020-LSky003). All these patients were followed until virus clearance (defined as two consecutive negative nucleic acid tests from throat swab samples). Of these 12 patients, 6 (50\%) were male. The median age was 22 [interquartile range (IQR), 7-39] years old. Two (16.7\%) patients were currently smoking. One patient $(8.3 \%)$ had hypertension. Six (50\%) patients were admitted due to COVID-19 related symptoms, of which 6 had fever and 4 had cough (Table 1). At the time of admission, none of these patients had severe respiratory symptoms necessitating oxygen therapy. There were also $6(50 \%)$ asymptomatic patients who were identified by screening of the close contacts with nucleic acid test.

On admission, 3 (25\%) patients had leukopenia $\left(<4 \times 10^{9}\right.$ cells $\left./ \mathrm{L}\right)$, with the lowest white blood cell of $2.21 \times 10^{9} / \mathrm{L}$. One $(8.3 \%)$ patient had lymphocytopenia $(<0.8 \times 109$ cells/L). 


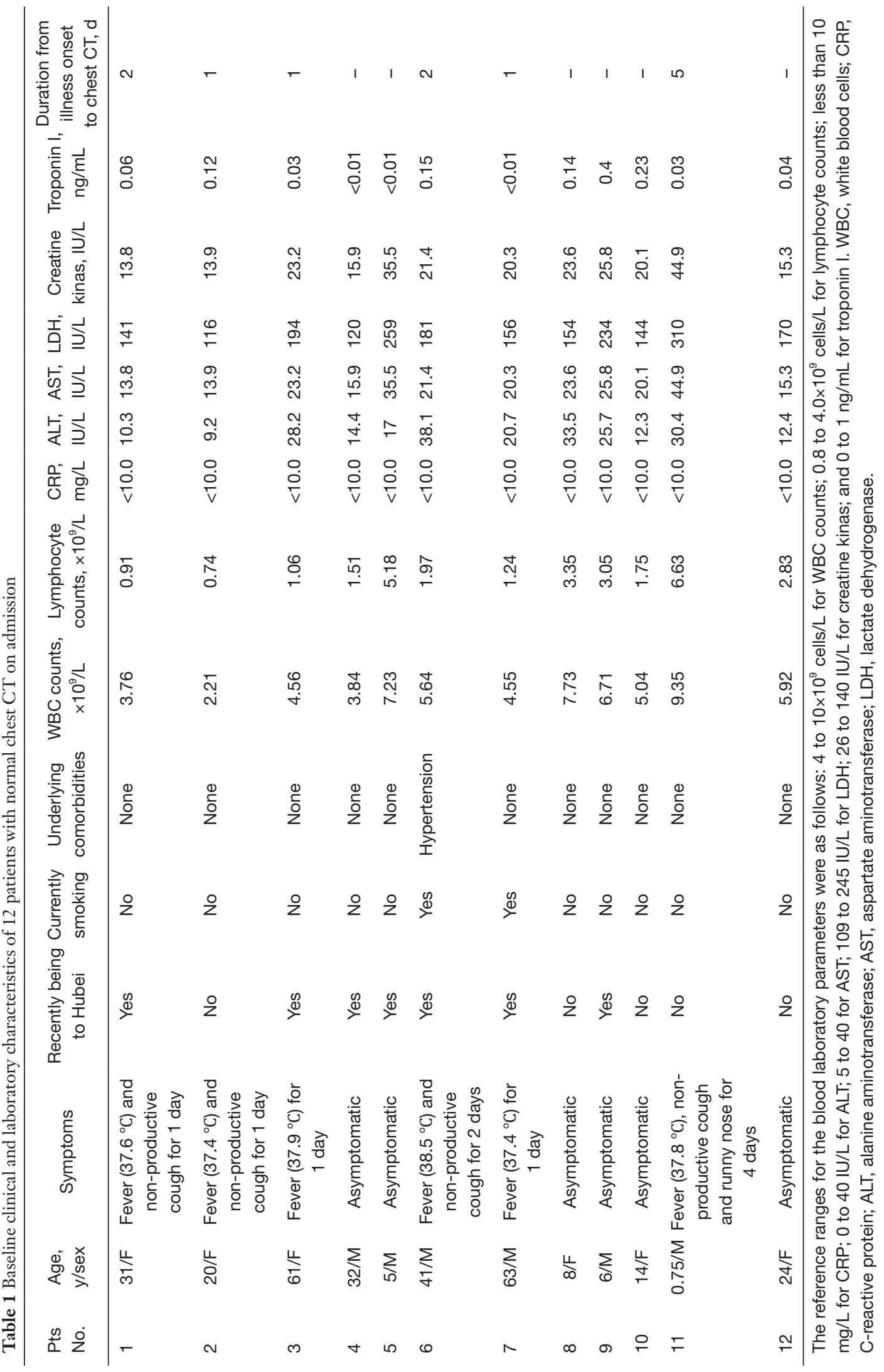



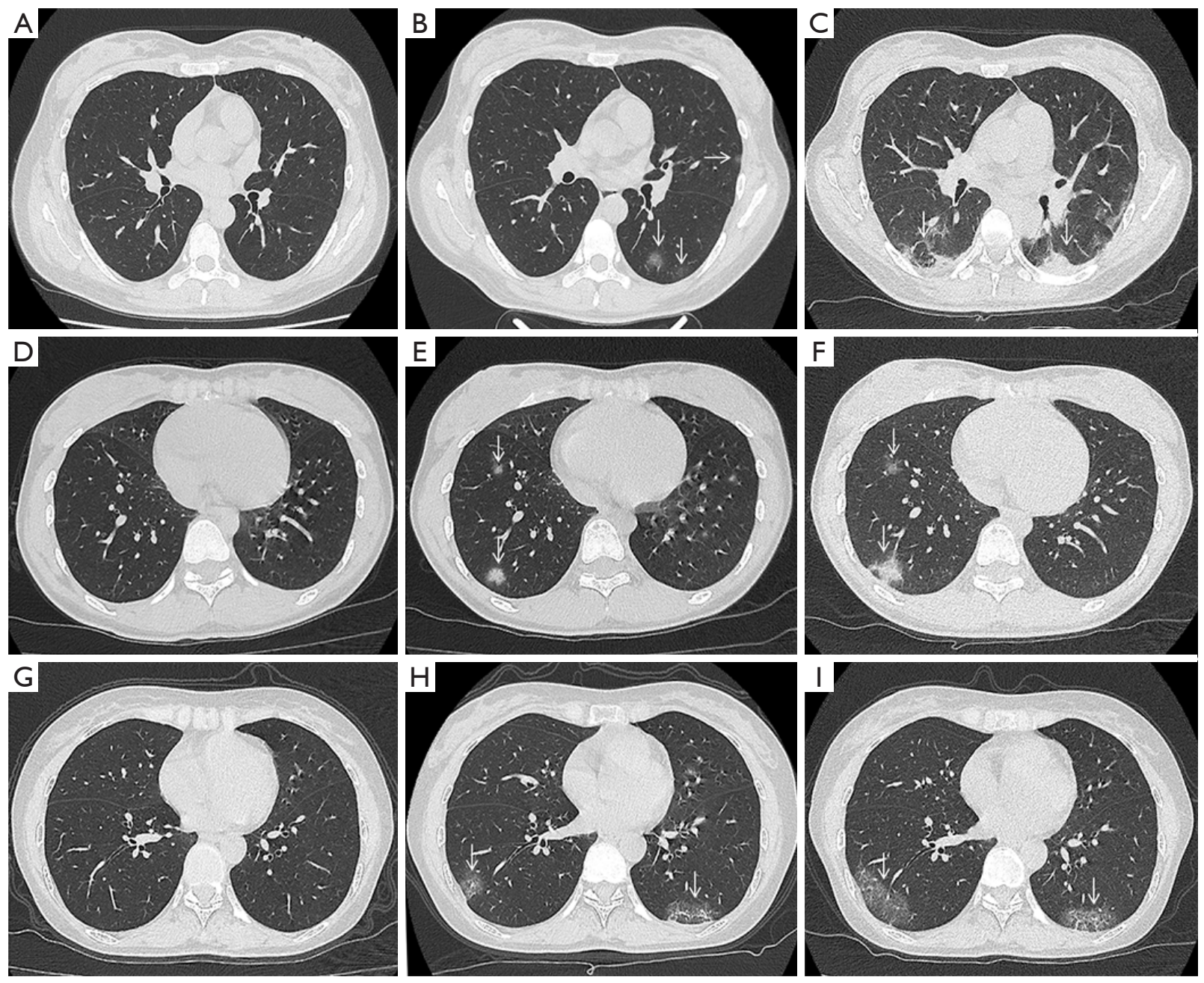

Figure 1 Dynamic changes of chest CT scans from 3 symptomatic patients. Case 1: chest CT scan was normal on admission (A). After two days, it showed multiple ground-glass opacities in left lung (B, arrows). A chest CT scan performed one week later showed further progression of pneumonia with bilateral lung exudations (C, arrows). Case 2: chest CT scan was normal on admission (D). A follow-up chest CT scan performed three days later revealed multiple ground-glass opacities in right lung (E, arrows). Continued progression of lung lesions was observed four days later (F, arrows). Case 3: chest CT scan was normal on admission (G). A follow-up chest CT scan performed three days later revealed multiple ground-glass opacities in peripheral of two lower lungs (H, arrows). Enlargement of the area of ground-glass opacities was shown on a chest CT scan after 3 days (I, arrows).

There was not significant change of liver and renal function, although $1(8.3 \%)$ patient had elevated level of aspartate aminotransferase (44.9 IU/L). Two (16.7\%) patients had elevated level of creatine kinase ( $>140 \mathrm{IU} / \mathrm{L})$. Serum lactate dehydrogenase level was increased in $2(16.7 \%)$ patients. None of the patients had abnormal levels of troponin, erythrocyte sedimentation rate and C-reactive protein. Procalcitonin level was marginally increased in $4(33.3 \%)$ patients. The median cycle threshold value of quantitative reverse transcription polymerase chain reaction, relatively representing SARS-
COV-2 viral load from the throat swab samples, was 33 (IQR, 21-36).

As mentioned previously, the studied patients had normal chest CT scans when they presented to the hospital. During hospitalization, chest CT scans were performed every 2-3 days until virus clearance. New occurrence of pulmonary abnormalities was found on the next chest CT scans in 3 symptomatic patients, all of which revealed typical viral pneumonia with multiple small patchy ground glass opacities (Figure 1). The 
baseline chest CT scans of these 3 patients were performed 1-2 days after symptom onset. Nevertheless, 9 patients had persistent normal chest CT scans; most of these patients (6/9) were asymptomatic infection. The findings in our study suggested that patients infected with SARS-COV-2 may not always develop pneumonia during the course of COVID-19. For these radiologically negative patients, if nucleic acid test or serologic test was not performed, the diagnose of COVID-19 would be missed. This, to some extent, highlighted the weakness of chest CT as a screening strategy for COVID-19, especially in patients with asymptomatic infection (13). It should be noted that 3 of 12 the patients with baseline normal chest CT developed lung lesions during following-up. All these patients had COVID-19 related symptoms. The baseline chest CT scans of these 3 patients were performed 1-2 days after symptom onset, suggesting that during the early stage of symptomatic infection with SARS-COV-2 chest CT scan may be "false" negative.

\section{Acknowledgments}

Funding: This study was funded in part by the project of Jiangsu province medical youth talent (QNRC2016059), Nanjing medical science and technique development foundation (ZKX17040). The funders had no role in study design, data collection and analysis, decision to publish, or preparation of the manuscript.

\section{Footnote}

Conflict of Interest: All authors have completed the ICMJE uniform disclosure form (available at http://dx.doi. org/10.21037/qims-20-539). The authors have no conflicts of interest to declare.

Informed Consent: Written informed consent was obtained from the patient for publication of this study and any accompanying images. A copy of the written consent is available for review by the Editor-in-Chief of this journal.

Open Access Statement: This is an Open Access article distributed in accordance with the Creative Commons Attribution-NonCommercial-NoDerivs 4.0 International License (CC BY-NC-ND 4.0), which permits the noncommercial replication and distribution of the article with the strict proviso that no changes or edits are made and the original work is properly cited (including links to both the formal publication through the relevant DOI and the license). See: https://creativecommons.org/licenses/by-nc-nd/4.0/.

\section{References}

1. Gorbalenya AE, Baker SC, Baric RS, de Groot RJ, Drosten C, Gulyaeva AA, Haagmans BL, Lauber C, Leontovich AM, Neuman BW, Penzar D, Perlman S, Poon LLM, Dmitry Samborskiy D, Sidorov IA, Sola I, Ziebuhr J. Severe acute respiratory syndrome-related coronavirusThe species and its viruses, a statement of the Coronavirus Study Group. Nature Microbiology 2020. doi: 10.1038/ s41564-020-0695-z.

2. Zhu N, Zhang D, Wang W, Li X, Yang B, Song J, Zhao X, Huang B, Shi W, Lu R, Niu P, Zhan F, Ma X, Wang D, Xu W, Wu G, Gao GF, Tan W, China Novel Coronavirus I, Research T. A Novel Coronavirus from Patients with Pneumonia in China, 2019. N Engl J Med 2020;382:727-33.

3. Hu Z, Song C, Xu C, Jin G, Chen Y, Xu X, Ma H, Chen W, Lin Y, Zheng Y, Wang J, Hu Z, Yi Y, Shen H. Clinical characteristics of 24 asymptomatic infections with COVID-19 screened among close contacts in Nanjing, China. Sci China Life Sci 2020;63:706-11.

4. Li Q, Guan X, Wu P, Wang X, Zhou L, Tong Y, Ren R, Leung KSM, Lau EHY, Wong JY, Xing X, Xiang N, Wu Y, Li C, Chen Q, Li D, Liu T, Zhao J, Li M, Tu W, Chen C, Jin L, Yang R, Wang Q, Zhou S, Wang R, Liu H, Luo Y, Liu Y, Shao G, Li H, Tao Z, Yang Y, Deng Z, Liu B, Ma Z, Zhang Y, Shi G, Lam TTY, Wu JTK, Gao GF, Cowling BJ, Yang B, Leung GM, Feng Z. Early Transmission Dynamics in Wuhan, China, of Novel CoronavirusInfected Pneumonia. N Engl J Med 2020;382:1199-207.

5. WHO. Situation Report-77. Available online: https://wwwwhoint/emergencies/diseases/novelcoronavirus-2019/situation-reports/

6. Ai T, Yang Z, Hou H, Zhan C, Chen C, Lv W, Tao Q, Sun Z, Xia L. Correlation of Chest CT and RT-PCR Testing in Coronavirus Disease 2019 (COVID-19) in China: A Report of 1014 Cases. Radiology 2020. [Epub ahead of print]. doi: 10.1148/radiol.2020200642.

7. Fang Y, Zhang H, Xie J, Lin M, Ying L, Pang P, Ji W. Sensitivity of Chest CT for COVID-19: Comparison to RT-PCR. Radiology 2020. [Epub ahead of print]. doi: 10.1148/radiol.2020200432.

8. Xie X, Zhong Z, Zhao W, Zheng C, Wang F, Liu J. Chest CT for typical 2019-nCoV pneumonia: relationship to negative RT-PCR testing. Radiology 2020. [Epub ahead 
of print]. doi: 10.1148/radiol.2020200343.

9. Wáng YXJ. A call for caution in extrapolating chest CT sensitivity for COVID-19 derived from hospital data to patients among general population. Quant Imaging Med Surg 2020;10:798-9.

10. Xu R, Du M, Li L, Zhen Z, Wang H, Hu X. CT imaging of one extended family cluster of corona virus disease 2019 (COVID-19) including adolescent patients and "silent infection”. Quant Imaging Med Surg 2020;10:800-4.

11. Hu Z, Song C, Xu C, Jin G, Chen Y, Xu X, Ma H, Chen W, Lin Y, Zheng Y, Wang J, Hu Z, Yi Y, Shen H. Clinical characteristics of 24 asymptomatic infections with
COVID-19 screened among close contacts in Nanjing, China. Sci China Life Sci 2020;63:706-11.

12. Bernheim A, Mei X, Huang M, Yang Y, Fayad ZA, Zhang N, Diao K, Lin B, Zhu X, Li K, Li S, Shan H, Jacobi A, Chung M. Chest CT Findings in Coronavirus Disease-19 (COVID-19): Relationship to Duration of Infection. Radiology 2020. [Epub ahead of print]. doi: 10.1148/ radiol.2020200463.

13. Wang YXJ, Liu WH, Yang M, Chen W. The role of CT for Covid-19 patient's management remains poorly defined. Ann Transl Med 2020;8:145.

Cite this article as: $\mathrm{Xu} C, \mathrm{Xu} Q, \mathrm{Du} C, \mathrm{Li} J, \mathrm{Hu} Z$, Yi Y. Radiological follow-up of twelve COVID-19 patients with initially normal chest CT. Quant Imaging Med Surg 2020;10(5):1153-1157. doi: 10.21037/qims-20-539 